\title{
- Uma visão de agribusiness
}

\section{- A look at agribusiness}

\author{
Francisco Armando de Azevedo Souza-CRMV-SPn ${ }^{\circ} 1794$ \\ Professor Assistente da Faculdade de Medicina Veterinária da Universidade de Marília
}

Faculdade de Medicina Veterinária
Universidade de Marilia - UNIMAR
Av. Hygino Muzzi Filho, 1001
CEP-17525-902 - Marilia -São Paulo
fone: (OXX14) 4338088 ;
fax: (0XX14) 4338691
e-mail:
azevedosouza@jau.sol.com.br

\section{RESUMO}

Este artigo tem como foco fornecer uma idéia ampla do que seja o agribusiness e a sua importância dentro do setor produtivo nacional. Para se inserir no futuro mercado de trabalho, os médicos veterinários deverão preocupar-se com as políticas agrícolas vigentes, bem como com todos os cenários de comercialização das commodities ou dos produtos industrializados, com o intuito de exercerem suas atividades profissionais e sua cidadania. Como exemplo, procura-se inserir a cadeia produtiva dos equídeos no agribusiness.

Unitermos: agribusiness, eqüinos, marketing.

\section{1- Uma visão de agribusiness}

$\underline{\mathrm{U}}$ ma das características da modernidade é a visão sistêmica, onde o todo é maior do que a soma das partes. Assim sendo, pode-se esperar um desenvolvimento harmonioso e sustentado das diferentes cadeias produtivas. Um dos setores, no Brasil, em que a visão tradicional tem sido mais desfigurada é a agricultura. A cadeia produtiva de alimentos e fibras, que constitui o maior complexo da sociedade brasileira, é ainda ignorada por ela e pelo governo, que insistem em não considerá-la como um todo, mas sim como segmentos isolados da economia (Figura 1). Essa visão deturpada dos governantes faz com que estas cadeias produtivas fiquem desarticuladas, com sérias dificuldades de concorrer com os demais países, principalmente pela falta de uma política agrícola de médio e longo prazos.

É bom frisar que o setor de agribusiness brasileiro é responsável por $32 \%$ do PIB, sendo composto pelo setor agropecuário (30\%), por indústrias $(9 \%)$ nos insumos para agricultura e $33 \%$ na agroindústria) e pelos serviços de distribuição (28\%) (Figura 2). Constitui-se, no presente momento, no único setor produtivo que vem apresentando superávit na balança comercial brasileira. Em 1997, a exportação agropecuária superou em US\$ 11,5 bilhões a importação de alimentos e fibras. No ano passado, com

\section{CMADAPRONINIA}

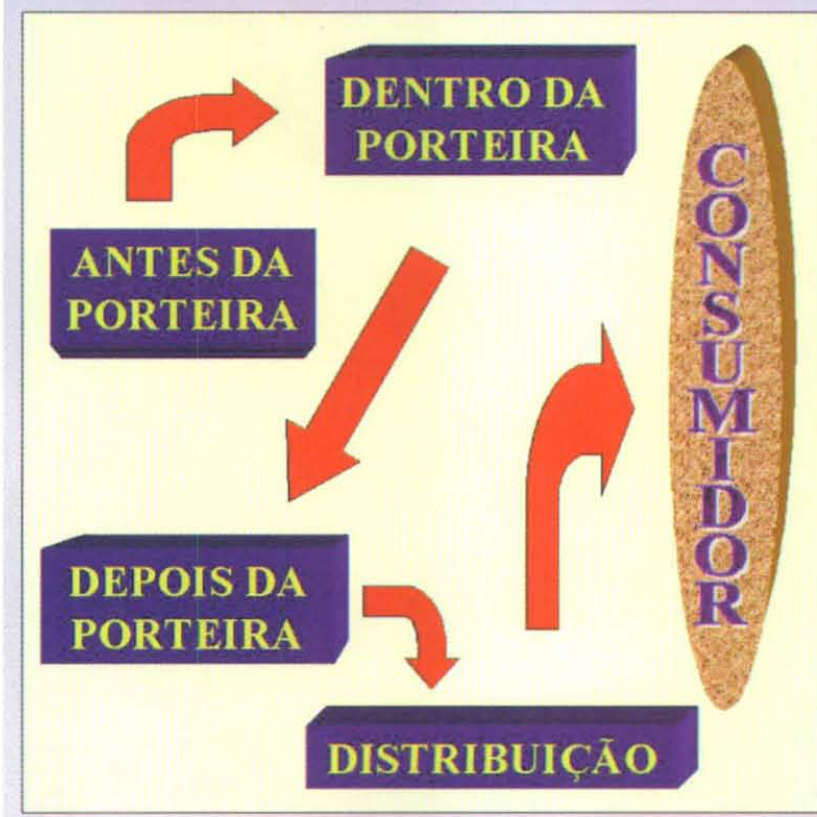

Figura 1 - Organograma da cadeia produtiva 


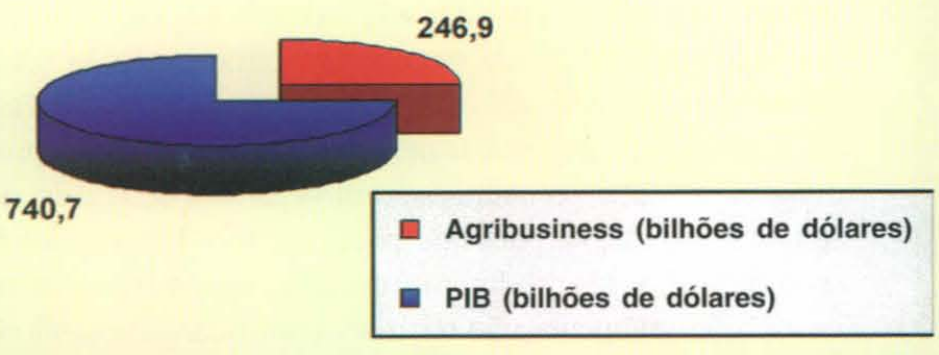

Figura 2 - Participação do Agribusiness no PIB do Brasil (1996)

preços muito ruins, o superávit ficou em US\$ 10,6 bilhões.

O Brasil optou por uma rápida industrialização, principalmente após a Segunda Grande Guerra, e isto fez com que ocorressem profundas mudanças na sociedade como um todo. Houve uma séria evasão de recursos da agricultura com destino ao processo de industrialização, e ao mesmo tempo, arrastou um contingente enorme de pessoas da área rural para as cidades. Com a criação de indústrias, o setor "antes da porteira" passou a oferecer uma série de novas tecnologias ao campo como adubos, defensivos, corretivos, medicamentos, máquinas e combustíveis. Assim sendo, o produtor rural passou a consumir estas novas tecnologias (Figura 3). Por outro lado, o esvaziamento do campo mudou o perfil urbano-rural, e, em menos de 40 anos, $70 \%$ da população passou a ser urbana, constituindo-se no segmento "depois da porteira", representado pelos setores de armazenamento, transporte, processamento e distribuição de produtos agrícolas e seus derivados. Após essas mudanças, o produtor rural passou a ser mais especializado, atendendo às exigências de um consumidor cada vez mais esclarecido.

O agribusiness já é conhecido nos países desenvolvidos desde 1957 e, por este sistema, entende-se a soma total das operações de produção, distribuição de insumos e novas tecnologias agrícolas; da produção propriamente dita; do armazenamento, do transporte, do processamento e distribuição dos produtos agrícolas e seus derivados.

$\mathrm{O}$ agribusiness brasileiro existe e está consolidado desde a década de 1970. Nesse sistema, várias cadeias produtivas são altamente organizadas e competitivas no mercado internacional, apesar dos enormes subsídios e taxas alfandegárias praticadas pelos países desenvolvidos. Sem sombra de dúvida, o Brasil, organizando as suas cadeias produtivas terá excelentes condições de aprimorar a segurança alimentar, ponto fundamental de seu desenvolvimento como sociedade justa e igualitária. Segurança alimentar é muito diferente de socorro alimentar, que é parte integrante de governos imediatistas, como temos visto ao longo dos anos. Segurança alimentar é aquela que garante a todas as pessoas, em todos os tempos, o acesso ao alimento necessário. Cabe a nós, profissionais das Ciências Agrárias, tomarmos consciência desses fatos e passarmos a formar opinião rapidamente, para que a sociedade como um todo e o governo, passem a reconhecer a importância do setor agribusiness para o desenvolvimento sustentado do País. O Brasil ainda está produzindo a metade das suas necessidades em grãos, para atingir a segurança alimentar, enquanto os demais países desenvolvidos produzem uma tonelada de grãos por habitante ano! O desafio é grande e duplo, pois precisamos aumentar a produção agrícola e aproximar os indicadores econômicos da população rural dos da urbana.

Em virtude da alta competitividade entre os países, os desafios deverão ser enfrentados de forma global. É extremamente importante lembrar que a atividade agrícola é de altíssimo risco, e que o produtor só vai voltar a produzir com toda tecnologia possível, quando tiver a segurança da demanda de seus produtos, o que certamente aumentará a sua renda líquida. Para atender a esses princípios, é necessário revalorizar a atividade agrícola e agroindustrial, de modo a atrair investimentos para o setor, tomando decisões de políticas agrícolas de longo prazo. Isso é fundamental para qualquer cadeia produtiva.

O Brasil é o país do futuro? Não há pergunta que mais incomode do que essa, mas existe uma certeza, sim: o Brasil é um dos países líderes no comércio mundial de alimentos e fibras, e com o maior potencial de expansão. Num primeiro momento, o grande mercado é representado por nós mesmos e não necessitamos desmatar um só hectare de terra, para atender a demanda interna e ter um excedente exportável. Para que isso venha a ocorrer, é necessário que haja políticas agrícolas duradouras e que o setor administrativo deste

\section{MOVIMENTA USS 300 BILHÕES 80 MILHÕES DE TON. GRÃOS. \\ 12 MILHÕES DE TON. CANA. 20 BILHÕES LITROS DE LEITE. EMPREGA 50\% DA POPULAÇÃO ATIVA DO BRASIL. CORRESPONDE A 35\% DO PIB BRASIL $65 \%$ PÓS - PORTEIRA: PROCESSAMENTO $\Rightarrow$ DISTRIBUIÇÃO}

Figura 3 - Agribusiness/Brasil 
SOUZA, F. A. A. Uma visão de agribusiness. / A look at agribusiness. / Rev. educ. contin. CRMV-SP / Continuous Education Journal CRMV-SP, São Paulo, volume 2, fascículo 3, p. 038 - 045, 1999.

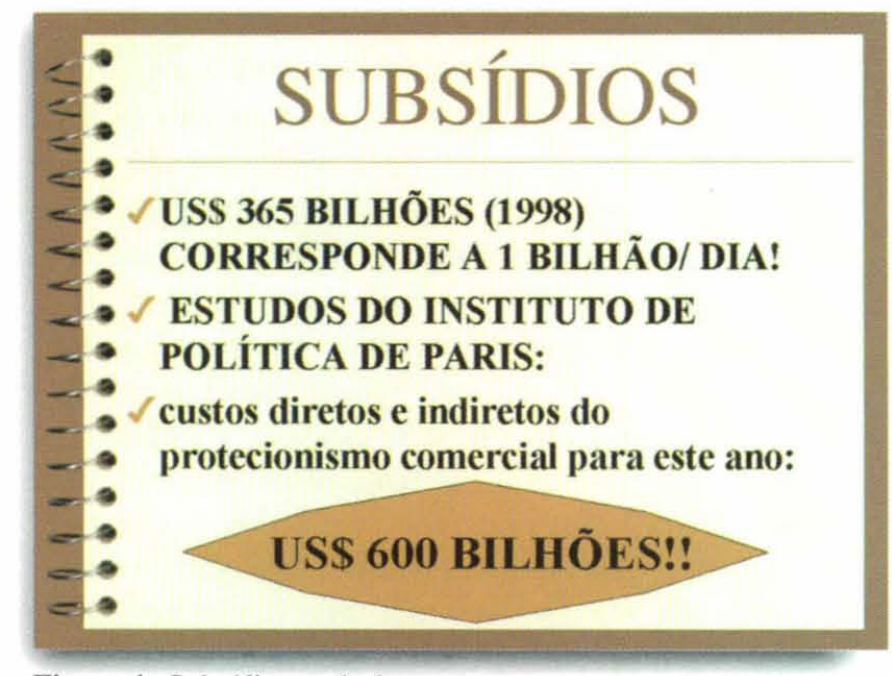

Figura 4 - Subsídios agrícolas

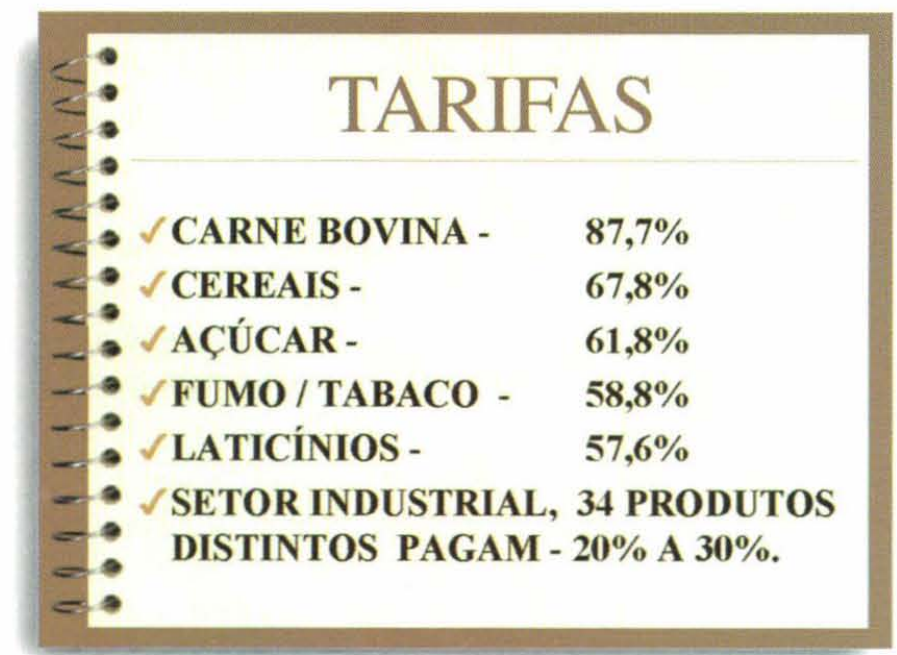

Figura 5 - Tarifas para U.E.

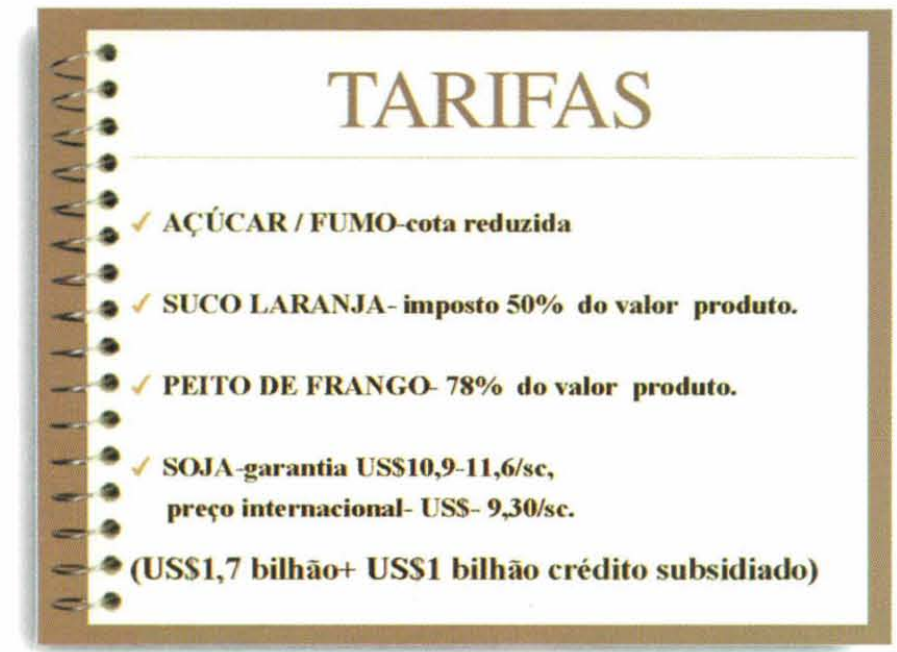

Figura 6 - Tarifas para USA/UE

país faça política externa à altura dos interesses nacionais.

Outro aspecto importante dentro do conceito de cadeia produtiva é aquele que informa a necessidade de haver um equilíbrio harmônico entre os elos desta cadeia, do "antes da porteira" até o consumidor final. A política é do "ganha-ganha", todos dependem de todos. Cada elo deve ter suas formas políticas de negociação para que cada setor obtenha o lucro desejado, mas sempre vendo o consumidor como o elo mais importante desta cadeia produtiva. Ao produtor rural, cabe preocupar-se em organizar-se dentro do seu setor produtivo para que possa exercer pressão sobre os demais elos. Os produtores rurais devem estar conscientes de que realmente não dá mais para ficar "chorando o leite derramado", esperando ajuda do governo.

$\mathrm{O}$ sucesso de um empreendimento no agribusiness depende do grau de organização interna de sua cadeia. Organizar-se é integrar informação. Informação é tecnologia. É ela que permite agregar valor ao produto. É importante saber também que informação tem custo agregado. Além disso, o agribusiness passa a ser responsável pela produção de alimentos dentro de um equilíbrio biológico, ou seja, dentro de um meio ambiente sustentado. Portanto, o meio ambiente deverá ser preservado por todas as cadeias produtivas. Acrescenta-se ainda que, sem uma organização das políticas de pesquisas, torna-se difícil integrar uma cadeia produtiva, e esta às demais.

Para a reunião da Organização Mundial do Comércio (OMC), também chamada de Rodada do Milênio, que aconteceu recentemente em Seattle (EUA), esperava-se que o Brasil exercesse um papel decisório nas questões ali debatidas como a redução dos subsídios e proteções dos países ricos a seus agricultores. É necessário um esforço concentrado do governo nesta área, coordenando setores privados, acadêmicos e os diferentes órgãos governamentais ligados ao tema, de forma a desenvolver linguagens e interesses comuns. Estudo do Instituto de Estudos Políticos de Paris, prefaciado por Patrick Messerlin, estima que os custos diretos e indiretos do protecionismo comercial aproximam-se, este ano, de US\$ 600 bilhões (Figuras 4, 5 e 6). Outra pesquisa, realizada pela OMC, revelou que o setor agrícola absorve dois terços dos gastos com o protecionismo comercial dos países desenvolvidos. Ano passado, essa conta foi da ordem de US $\$ 365$ bilhões, ou seja, um bilhão por dia.

Os cinco produtos mais tarifados para entrar na União européia são: 1) carne bovina, $87,7 \%$; 2) cereais, $67,8 \%$; 3) açúcar, 61,8\%; 4) fumo ou tabaco, 58,8\%; 5) laticínios, $57,6 \%$. No setor industrial, trinta e quatro produtos distintos pagam entre $20 \%$ e $30 \%$. Todo este processo de subsídios levou 40 anos para ser implantado, e, agora, conseguir derrubá-lo, é uma tarefa árdua, onde o bloco europeu reluta em retirá-lo enquanto os EUA concordam 
em acabar com o subsídio, uma vez que a União Européia faça o mesmo. O Brasil, pelas suas enormes potencialidades de produção de alimentos e fibras, mesmo na forma de commodities, tem reais condições de entrar fortemente nos mercados. Para tanto, é preciso "arrumar a casa", organizando o processo decisório internamente e no próprio Mercosul. Os nossos concorrentes já estavam no campo de batalha há tempos e nós mal havíamos começado a nossa articulação para a Rodada do Milênio. A realidade é que precisamos entrar nesta batalha com muita firmeza e boa base técnica e, principalmente, com objetivos muito bem definidos, onde todos os setores interessados estejam articulados e falando a mesma linguagem.

Para se inserir no mercado de trabalho, os técnicos das Ciências Agrárias deverão, a partir dos próximos anos, preocupar-se com as políticas agrícolas vigentes, bem como com todos os cenários de comercialização das commodities, ou dos produtos industrializados, com o intuito de exercerem sua atividade profissional e sua cidadania. Não é mais possível trabalhar, ou produzir um alimento, qualquer que seja este, sem olhar a cadeia produtiva deste produto para a tomada de decisões.

\section{2- Exemplo para inserir uma cadeia produtiva dentro do agribusiness: a cadeia produtiva dos equiídeos}

Podemos inserir os equídeos no setor agribusiness, pois estes animais, ou melhor, a carne desses animais faz parte do que se chama cardápio cultural de alguns povos. Por outro lado, quando se observa de forma sistêmica a cadeia produtiva dos equídeos, verifica-se que há inserção de diferentes segmentos de outra cadeias produtivas na produção dos cavalos, como o setor de rações, fibras, medicamentos, vacinas e outros. (Figura 7). Além disso, existe um consumidor final, que utiliza o animal tanto na forma de alimentos, como para entretenimento e lazer. Além desses fatores, é importante lembrar que o cavalo acompanha o Homem há muito tempo, em todo o seu processo evolutivo. No Brasil, o sistema de informações é extremamente lento e falho para outras cadeias produtivas mais expressivas que a dos equídeos, e, portanto, não se dispõe de informações confiáveis. Porém, o último censo Agropecuário Brasileiro, realizado em 1995 (Figura 8), apontou que a população dos equídeos no país era:

\begin{tabular}{|l|l|}
\hline Asininos & 1.344 .155 \\
\hline Muares & 1.997 .783 \\
\hline Eqüinos & 6.394 .145 \\
\hline Total & 9.736 .083 \\
\hline
\end{tabular}

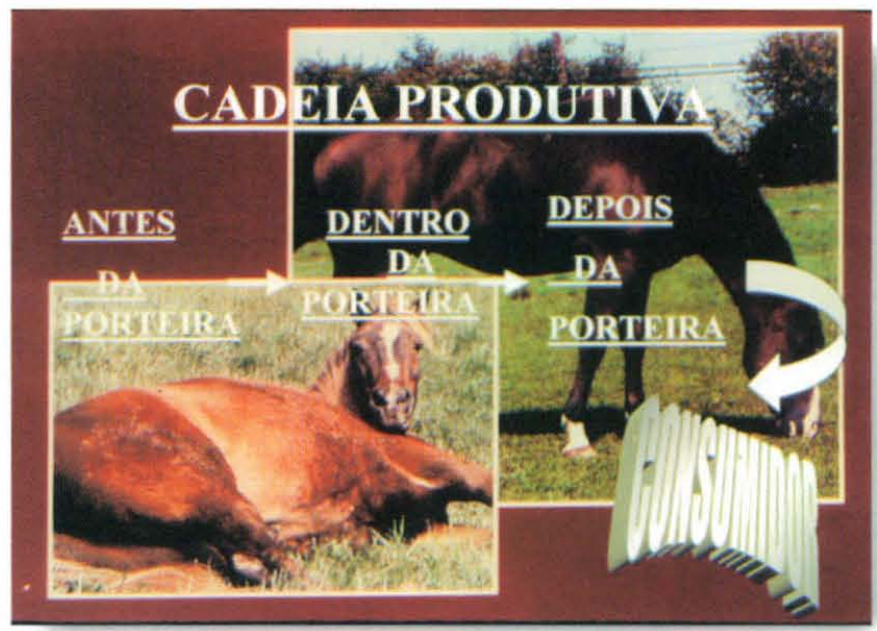

Figura 7 - Cadeia produtiva de eqüídeos

Os Estados Unidos possuem um rebanho de eqüinos da ordem de 6. 931.000 de cavalos, com 7,1 milhões de pessoas envolvidas, num valor agregado de 25,3 bilhões de dólares, gerando empregos diretos na ordem de 338.500 postos. Os Estados de Texas, Califórnia, Flórida, Oklahoma, Illinois, Colorado, Ohio, Kentucky e New York possuem 3.000.000 de cavalos. Esses Estados movimentam, com a indústria eqüina, 48 bilhões de dólares e são responsáveis pela geração de 174.000 postos de empregos diretos e outros 601.000 de postos indiretos (Figura 9). De acordo com as estatísticas americanas, há uma previsão de crescimento do número de pessoas interessadas em cavalo, na ordem de 13,3 milhões, o que corresponde a

REGIÃO GEOGRÁGICA

\begin{tabular}{lrrrr} 
& ASININO & MUAR & EQÜINO & TOTAL \\
CENTRO & 13.504 & 15.848 & 1.061 .097 & 1.228 .449 \\
OESTE & & & & \\
NORDESTE & 1.224 .028 & 900.290 & 1.697 .063 & 3.821 .381 \\
NORTE & 53.083 & 223.713 & 638.826 & 915.622 \\
SUDESTE & 48.713 & 585.044 & 1.811 .121 & 2.444 .878 \\
SUL & 4.827 & 134.888 & 1.186 .038 & 1.325 .735 \\
TOTAL & 1.344 .155 & 1.997 .783 & 6.394 .145 & 9.736 .083 \\
& & & & \\
& & & & \\
SÃO PAULO & 8.596 & 163.267 & 615.141 & 787.004 \\
& & & & \\
& FONTE IBGE PESQUISA PECUARIA MUNICIPAL-1995 \\
\hline
\end{tabular}

Figura 8 - Efetivo do rebanho brasileiro conforme a região (Censo 1995). 
SOUZA, F. A. A. Uma visão de agribusiness. / A look at agribusiness. / Rev. educ. contin. CRMV-SP / Continuous Education Journal CRMV-SP, São Paulo, volume 2, fascículo 3, p. 038 - 045, 1999.

$10 \%$ de aumento por ano. Há uma expectativa de $5 \%$ de crescimento anual para o número de cavaleiros, ou seja, um aumento de 8 milhões de pessoas que querem andar a cavalo. Além disso, espera-se um aumento de 2,5\% no número de proprietários de cavalos, o que corresponde a 2,2 milhões de pessoas.

Ainda nos EUA, são abatidos 100.000 animais destinados para consumo humano. Ao que tudo indica, há uma tendência de aumentar esses abates, mas, para tanto, as entidades ligadas ao cavalo têm pressionado o governo americano para criar normas modernas de transporte, abate humanitário e normas higiênico-sanitárias nos estabelecimentos de abate de eqüinos. Há uma pressão muito forte em alguns Estados, para proibir o transporte e o abate de eqüinos destinados ao consumo humano, pois consideram que esta carne não faz parte do cardápio cultural do americano. Esta lei já foi sancionada no final do ano passado no Estado da Califórnia. Com isso, abre-se um novo campo de pesquisa e de negócios dentro da indústria eqüina, que é o campo da geriatria eqüina. Infelizmente, não temos os números das estatísticas brasileiras no que se refere a cavalos.

\begin{tabular}{|c|c|c|c|c|c|c|}
\hline \multicolumn{7}{|c|}{$\begin{array}{l}\text { ECONOMIC IMPACT OF THE HORSE } \\
\text { INDUSTRY IN THE UNITED STATES } \\
\text { (THE HORSE APRIL/97) }\end{array}$} \\
\hline STATE & $\begin{array}{l}\text { GOODS \& } \\
\text { SERVICES }\end{array}$ & $\begin{array}{c}\text { ECONOMIC } \\
\text { IMPACT }\end{array}$ & $\begin{array}{c}N^{o} \\
I N V O L V E D\end{array}$ & $\begin{array}{l}\text { FTE } \\
\text { JOBS }\end{array}$ & $\begin{array}{c}\text { EMPLOYEM } \\
\text { ENT } \\
\text { IMPACT }\end{array}$ & $\begin{array}{c}N^{o} \\
H O R S E S\end{array}$ \\
\hline CALIFORNIA & $\begin{array}{c}\$ 3,4 \\
\text { BILLION }\end{array}$ & $\begin{array}{c}\$ 11,4 \\
\text { BILLION }\end{array}$ & 720.500 & 36.000 & 124.400 & 642.000 \\
\hline COLORADO & $\begin{array}{c}\$ 754 \\
\text { MILLION }\end{array}$ & $\begin{array}{c}\$ 2,6 \\
\text { MILLION }\end{array}$ & 191.600 & 7.700 & 30.800 & 194.00 \\
\hline FLORIDA & $\begin{array}{c}\$ 2,2 \\
\text { BILLION }\end{array}$ & $\begin{array}{c}\$ 6,5 \\
\text { BILLION }\end{array}$ & 244.200 & 18.600 & 72.200 & 299.000 \\
\hline IDAHO & $\begin{array}{c}\$ 179 \\
\text { MILLION } \\
\end{array}$ & $\begin{array}{c}\$ 0,9 \\
\text { BILLION }\end{array}$ & 112.500 & 4.700 & 15.500 & 120.00 \\
\hline ILLINOIS & $\begin{array}{c}\$ 1,3 \\
\text { BILLION }\end{array}$ & $\begin{array}{c}\$ 3,8 \\
\text { BILLION }\end{array}$ & 214.000 & 15.900 & 49.400 & 219.000 \\
\hline KENTUCKY & $\begin{array}{c}\$ 1,2 \\
\text { BILLION } \\
\end{array}$ & $\begin{array}{c}\$ 3,4 \\
\text { BILLION }\end{array}$ & 128.800 & 16.600 & 52.900 & 150.00 \\
\hline MARYLAND & $\begin{array}{c}\$ 614 \\
\text { MILLION }\end{array}$ & $\begin{array}{c}\$ 1,5 \\
\text { BILLION }\end{array}$ & 82.900 & 6.700 & 20.000 & 82.000 \\
\hline NEW YORK & $\begin{array}{c}\$ 1,7 \\
\text { BILLION }\end{array}$ & $\begin{array}{c}\$ 4,8 \\
\text { BILLION }\end{array}$ & 258.100 & 12.800 & 49.500 & 146.000 \\
\hline ОНІо & $\begin{array}{c}\$ 776 \\
\text { MILLION }\end{array}$ & $\begin{array}{c}\$ 2,8 \\
\text { B ILLION }\end{array}$ & 263.500 & 11.400 & 36.200 & 192.000 \\
\hline ОКLАНОМА & $\begin{array}{c}\$ 762 \\
\text { MILLION } \\
\end{array}$ & $\begin{array}{c}\$ 3,3 \\
\text { BILLION }\end{array}$ & 214.600 & 14.500 & 51.500 & 278.000 \\
\hline TEXAS & $\begin{array}{c}\$ 1,7 \\
\text { BILLION }\end{array}$ & $\begin{array}{c}\$ 7,1 \\
\text { BILLION } \\
\end{array}$ & 606.300 & 29.100 & 98.800 & 678.000 \\
\hline TOTAL & $\begin{array}{c}\$ 14,5 \\
\text { BILLION }\end{array}$ & $\begin{array}{c}\$ 48,1 \\
\text { BILLION }\end{array}$ & 3.036 .000 & 174.000 & 601.200 & 3.000 .000 \\
\hline
\end{tabular}

Figura 9 - Economia da indústria eqüina USA.
O Jockey Clube de São Paulo realizou um trabalho de pesquisa em 1979, em que procurou informar à população a importância social do cavalo e no qual constatou que a indústria eqüina paulista empregava o correspondente a duas empresas Autolatina, produtora de automóveis, fato este que mostrou a importância do cavalo como gerador de divisas e de empregos.

Assim sendo, como se justifica querer comparar a força da indústria eqüina americana com a brasileira, sabendo-se do poder aquisitivo do povo americano e de sua melhor distribuição de renda? Na realidade, o Brasil viveu um grande momento na produção eqüina nos anos 80 e início dos anos 90, mas com a espiral inflacionária da época, o cavalo păssou a ser uma "moeda", cujos valores estavam distantes da realidade brasileira. Além disso, houve a coincidência de um "boom" tecnológico na área eqüina, o que associado com o alto valor do cavalo, multiplicou excessivamente a população de eqüinos do Brasil. Com as sucessivas crises econômicas e também com a vigência do plano real, esses valores alteraram-se e a escala de prioridades da população inverteu-se novamente, indo ao encontro do estudo da escala das necessidades básicas do homem segundo Maslow, que classifica num estágio inicial da sociedade a necessidade de atender as suas necessidades fisiológicas como sobrevivência, alimentação, moradia e roupa. Num segundo patamar, estaria o Homem preocupado com a sua segurança, estabilidade no lar, no emprego, com a sua proteção e da sua família. À medida que ocorre o crescimento humano em direção à sua autorealização, ao seu autodesenvolvimento, a sua auto estima e auto expressão, há reais possibilidades de a sociedade, desde que seja culturalmente interessante como forma de lazer e companhia, "consumir" cavalo, comprar cavalo. Isto sugere que passou a ocorrer melhor distribuição de renda, que processos fisiológicos e de segurança estão fáceis de serem controlados, permitindo, assim, que o cavalo seja possível de ser viabilizado dentro 
da sociedade, tal como é viajar, comprar um carro e outras coisas mais.

Isto posto, nestes últimos anos, a indústria eqüina passou a adequar-se à nova ordem mundial de baixar custos de produção, aumentar a competitividade e racionalizar os sistemas de produção de cavalos. Na realidade, o que parecia estar harmonioso, sistêmico, estava desarrumado, desarticulado, de maneira que cada elo da cadeia produtiva dos cavalos estava produzindo para si, e tudo sendo consumido dentro do seu próprio elo. O consumidor final era fictício, comprando cavalos com o único propósito ganhar dinheiro com a moeda "cavalo".

Para que o negócio cavalo passe a integrar o sistema agribusiness, é necessário que os diferentes atores da cadeia produtiva passem a se organizar, integrando a informação dos diferentes elos da cadeia de forma que esta integração passe a gerar mais tecnologia. Acontecendo esse processo, a agregação de valor ao produto final será realizado. Não ocorrendo essa integração, provavelmente não haverá uma agenda de trabalho e isso propiciará a oportunidade de ocorrerem ações dispersas descoordenadas, que não estejam interligadas e em direção ao empreendimento cavalo.

\section{3 - A inserção do clínico veterinário especialista em eqüinos na cadeia produtiva}

Qualquer cadeia produtiva organizada de forma sistêmica deverá apresentar entre seus diferentes atores, profissionais especializados que se constituirão em importantes elos para que ela funcione de forma harmônica.

Os médicos veterinários especialistas em eqüinos, especificamente os cirurgiões, compõem um estratégico elo dentro da cadeia produtiva porque, segundo informações do NATIONAL ANIMAL HEALTH MONITORING SYSTEM (NAHMS), localizado nos EUA, no ano de 1997, a síndrome cólica foi a principal causa de morte dos equídeos ( $17,6 \%$ ) com mais de 30 dias de idade. A taxa de mortalidade em potros até 30 dias de idade foi de $3,6 \%$, enquanto que para aqueles com idade de 31 dias até 6 meses foi de $1,4 \%$, para animais de 6 meses até 5 anos a taxa foi de $1,5 \%$ e para os animais de 20 anos ou mais foi de $11,1 \%$. Pela análise destes dados e pela seriedade existente na fonte da informação, conclui-se que realmente temos a necessidade de profissionais altamente especializados em atender pacientes portadores de cólica. Não temos a menor dúvida em afirmar que, se há necessidade de profissionais específicos para esta abordagem clínico-cirúrgica, quantos outros, também especialistas, não são necessários para que a cadeia produtiva dos equídeos funcione de forma harmônica, procurando atender da melhor forma possível o consumidor final de cavalos, nas diferentes formas de apresentação deste produto!

Nos Estados Unidos da América existe uma classe de médicos veterinários especialistas em eqüinos que funciona há 46 anos! Esta entidade é responsável pelo monitoramento de toda a cadeia produtiva, nos seus diferentes elos, que fazem com que o negócio cavalo represente algo próximo a US $\$ 48$ bilhões somente em 11 Estados que possuem um grande quantidade de cavalos! A American Association of Equine Practitioners (AAEP) preocupa-se com os mais diferentes aspectos da prática veterinária eqüina, mas o foco, a meta, para o corrente ano e para a virada do milênio é orientar os seus quadros a terem noções mais refinadas do negócio cavalo, fazendo com que os técnicos passem a ter uma visão moderna dos processos econômicos, administrativos e financeiros, independentemente da sua área de atuação, de forma que possam atender cada vez melhor o proprietário de cavalos, procurando preservar o veterinário de qualquer envolvimento jurídico, sempre objetivando a satisfação do proprietário de cavalos. Esta entidade tem a finalidade de promover a saúde e o bem estar dos cavalos, promover o desenvolvimento profissional entre os seus membros, angariar recursos e formar lideranças para o benefício da indústria eqüina americana.

Todos os anos, a AAEP organiza um evento técnico científico de altíssimo nível, com o intuito de reciclar e informar os veterinários associados em âmbito mundial. Também já ofereceu aos seus associados bem como a toda cadeia produtiva, ferramentas de marketing, procurando orientar os médicos veterinários sobre como trabalhar os proprietários de cavalo, de forma que a lembrança do veterinário torne-se marcante e que este seja consultado todas as vezes que se fizer necessária a opinião de um técnico especializado.

A AAEP atua muito próxima dos proprietários de cavalos, orientando-os a consultá-la, desde o momento da compra do animal, ou sobre qualquer tipo de problema que venha a apresentar. Dispõe de um serviço telefônico 24 horas ao dia, durante todos os dias, da semana. Isso permite que, de qualquer lugar que um proprietário de cavalo esteja com o seu animal, disponha de serviços especializados. Esta agregação de valor é fundamental para que o negócio cavalo prospere, fazendo com que a cadeia produtiva de cavalos seja cada vez mais forte nos EUA. Esta entidade também orienta os graduandos em veterinária para estágios e fornece bolsas para auxílio, bem como financia projetos de pesquisa junto às universidades americanas. Esse exemplo de coordenação seria fundamental existir no Brasil, para que a cadeia produtiva funcionasse de forma sistêmica. 
SOUZA, F. A. A. Uma visão de agribusiness. / A look at agribusiness. / Rev. educ. contin. CRMV-SP / Continuous Education Journal CRMV-SP, São Paulo, volume 2, fascículo 3, p. 038 - 045, 1999.

\section{4- A relação clínico / proprietário}

Esta relação constitui-se no elo mais forte da cadeia, mas também o mais sensível a qualquer conduta indesejada do profissional veterinário. Neste aspecto, o clínico deverá sair da redoma que o cerca e passar a manter um relacionamento mais pessoal com seus clientes, propiciando que a empatia sempre cresça de ambos os lados (Figura 10). Esta é a meta atual, continuar vivo na lembrança do proprietário, na medida da satisfação completa com os seus serviços.

Para que esse processo ocorra espontaneamente, o clínico deverá sempre estar disposto a explicar todos os procedimentos que pretenda tomar, fornecendo elementos fáceis de serem percebidos pelo cliente, para que possa tomar a decisão mais acertada para o animal e que atenda as suas expectativas. A formação dos médicos veterinários, em geral, não atende às necessidades mínimas, indispensáveis para que o clínico saiba e aprimore o seu relacionamento com os seus clientes. Para tanto, deverá buscar informações mais precisas de recursos humanos, os quais fornecerão os subsídios sólidos para melhorar esta relação. O médico veterinário, atuante na clínica eqüina, precisa mudar para aperfeiçoar sempre este relacionamento. Atuando com a ajuda destas ferramentas administrativas, certamente ele estará vivo na lembrança dos seus clientes, o que certamente facilitará AGREGAR VALOR AO SERVIÇO PRESTADO.

O clínico veterinário atuante deverá ser sempre um formador de opinião, disseminando informações que certamente farão com que os seus clientes continuem a confiar em sua empresa, percebendo que

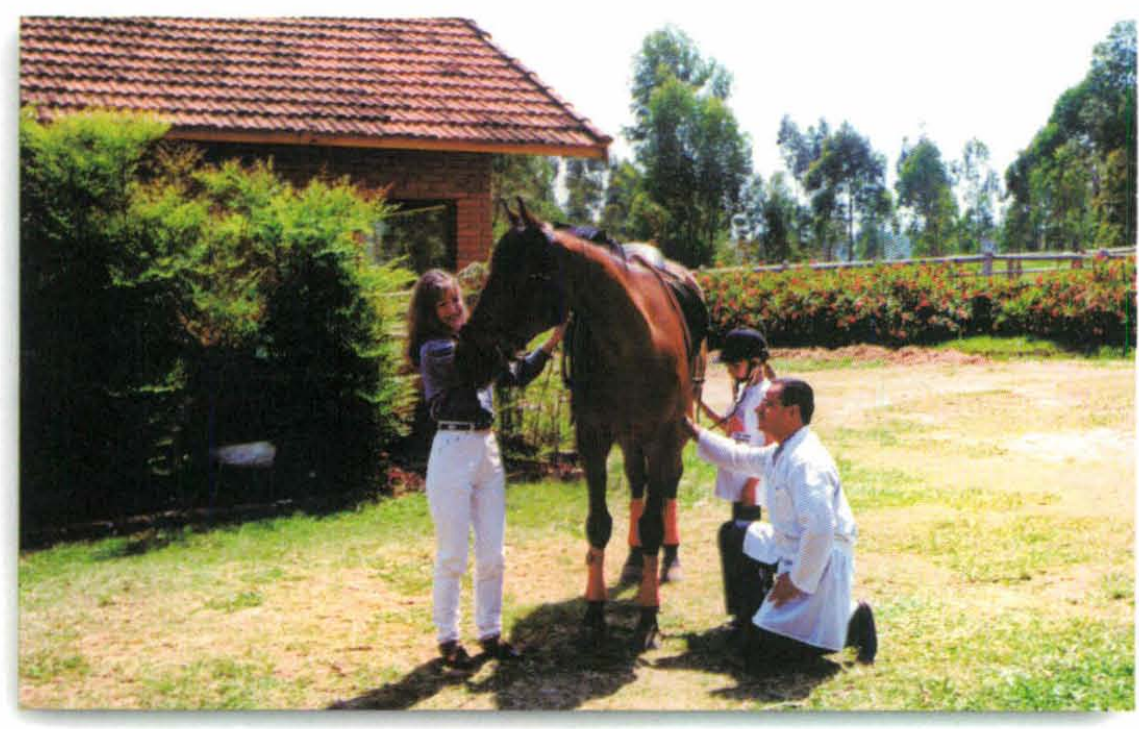

Figura 10 - Inter-relação profissional / proprietários. benefícios mútuos são importantes. É a relação "ganha/ganha".

\section{5 - O clínico veterinário especialista em eqüino e o marketing}

Aprender a vender a sua imagem, a sua competência técnica, é tão importante quanto fazer uma boa cirurgia. Ajudar a vender a imagem de que o cavalo, como negócio, é interessante, de que é o melhor animal para companhia, ou ainda, disseminar a idéia de que possuir cavalo faz bem a saúde, é nossa obrigação. Se olharmos para as demais cadeias produtivas como a do leite e a das carnes vermelhas e brancas, percebemos que a venda da idéia de que aquele produto é melhor que o do concorrente, é crucial para sobrevivência do produto ou da marca. Quem vende a nossa marca? Quem vende a idéia na mídia que ter cavalo para passear nos fins de semana é tão bom quanto andar de carro, de jet ski ou de bicicleta?

Como exemplo, citamos a suinocultura, que está preparando, pela primeira vez, uma campanha nacional para vender a idéia de que a carne suína faz bem a saúde. Mas, enquanto não tinha sido divulgada, uma empresa de produtos de limpeza lançou uma propaganda onde mostra um suíno caminhando em ambiente familiar com os pés sujos na cozinha, no banheiro, passando uma mensagem ao consumidor urbano que suíno é porco, que porco é sinal de sujeira! Aonde está a preocupação das associações de classe de profissionais, da cadeia produtiva dos equídeos em aparecer na mídia vendendo o negócio cavalo? Aonde estão os veterinários, cirurgiões eqüinos, divulgando o seu trabalho, implantando a sua marca para a sociedade em geral, ou mesmo junto as entidades que trabalham com eqüinos?

Esses profissionais precisam estar cientes que não basta mais ser um excelente fazedor de alguma coisa, precisam, sim, usar ferramentas modernas da administração e passar a preocuparem-se em movimentar pessoas a um bem comum, a toda classe que ele pertence, ou seja, fomentar o negócio cavalo! O trabalho em equipe, o processo da administração participativa são duas das mais importantes ferramentas, para que possamos fazer as coisas acontecerem!

Júlio Ribeiro, um dos maiores especialistas em marketing diz: "O sucesso de qualquer empreendimento está 
nas PESSOAS. O êxito não se mede pelo que você SABE, mas pelo que você FAZ com o que você SABE"

Assim sendo, para mantermos o negócio cavalo crescendo, TODOS os atores da cadeia produtiva deverão estar atuando de forma harmônica, cada um dentro do seu elo. Isto é fundamental !

\section{6 - Conclusão}

A decisão do que fazer é uma prerrogativa particular e, em alguns casos, está voltada para o atendimento de algum mercado específico. Uma reflexão sobre este aspecto é importante, uma vez que, de modo geral, a maioria dos envolvidos em produção de cavalos, direta ou indiretamente, produzirá para atender a um mercado mais amplo. Quanto ao sistema de produção, faz-se necessário que as diferentes áreas e disciplinas atuem em conjunto dentro de uma visão sistêmica da cadeia produtiva de cavalos. As diversas alternativas de manejo têm como objetivo principal a otimização do desempenho REPRODUTIVO e PRODUTIVO dos rebanhos. Portanto, o enfoque deve estar voltado à prevenção de doenças, ao atendimento das emergências e às exigências nutricionais nas diferentes fases da vida dos eqüinos; bem como explorar o potencial genético dos eqüinos, cada um dentro de sua especialidade funcional.

A pesquisa, o ensino e a extensão em eqüinocultura deverão adequar-se para enfocar o negócio cavalo com visão de cadeia produtiva, aumentando a sua competitividade em relação às outras cadeias.

\section{SUMMARY}

The objective of this article is to present general concepts and the importance of agribusiness in the Brazilian agricultural production. The next years will mark the focus of the veterinary on agriculture policies and on the possibilities of commodity and industrial food product commerce. Horse business is analysed as an example.

Key words: agribusiness, food product commerce, commodities horses, marketing.

\section{BIBLIOGRAFIA DE APOIO}

1 - AMERICAN ASSOCIATION OF EQUINE PRACTITIONERS- REPORTS. Lexington, Kentucky. 1998.

2 - ARAÚJO, N. B. et al. Complexo Agro-industrial. O Agribusiness brasileiro. São Paulo: Suma Econômica, 238p.

3 - ASSOCIAÇÃO BRASILEIRA DE AGRIBUSINESS- ABAG. Segurança Alimentar "Uma abordagem de Agribusiness”. São Paulo: ABAG, 1993, 162p.

4 - BATAlHA, M. O . et al. Gestão agro-industrial. São Paulo: Atlas, 1997, v.1, 323p.

5 - CAMPOS, V. F. T.Q.C. Controle da Qualidade Total ( no estilo japonês) . $4^{\circ}$ ed. Rio de Janeiro: Bloch, 1992, 229p.

6 - DESOUZART, O. Obstáculos não tarifários ao livre comércio na era da globalização, ter ou não, eis a questão. In. REUNIÃO ANUAL DA SOCIEDADE BRASILEIRA DE ZOOTECNIA, 35, 1998, Botucatu, São Paulo. Anais. Botucatu, 1998. P. 289.

7 - FARINA, E. M. M. Q.; ZYLBERSZTAJN. D. Competitivi-dade e organização das cadeias produtivas agroindustriais- trabalho realizado para II ICA- Instituto
Interamericano de Cooperação para Agricultura- 1994, $62 \mathrm{p}$.

8 - FARINA, E. M. M. Q. et al. Competitividade: mercado, estado e Organização. São Paulo: Singular, 1997, 286p.

9 - KFOURI, A. C. Administração rural. Série Educação Continuada. São Paulo: Paulicéia, 1995, 268p.

10 - MACHADO FILHO, C. A. P. et al. Agribusiness europeu. São Paulo: Pioneira, 1996, 132p.

11 - MEgIDO, J. L. T.; XAVIER, C. Marketing \& Agribusiness. São Paulo: Atlas, 1994, 202p.

12 - PINAZZA, L. A.; ARAÚJO, N. B. Agricultura na virada do século XX - Uma visão de agribusiness. São Paulo: Globo, 1993, 166p.

13 - PREÇOS AGRÍCOLAS. Piracicaba, São Paulo, 1995-.

14 - RIBEIRO, J. Fazer Acontecer. São Paulo: Cultura editores Associados, 1994, 257p.

15 - THE HORSE. Lexington, Kentucky. 1994-. 